\title{
Application and Research on Shared Ontology Model of Coal Mine Emergency Cases
}

\author{
Yonghong Cui \\ School of Resource and Safety Engineering, \\ China University of Mining and Technology, \\ Beijing, China
}

\begin{abstract}
As the stable operation in coal production is threaten by many kinds of safety accidents seriously, doing research on emergency knowledge in the field of coal mine safety production can provide several for emergency decision, which is of great importance. This paper designed and developed coal mine emergency case ontology model in order to solve problem of case knowledge sharing and semantic conflicts in the coal mine emergency field. Lastly, this paper constructed coal mine emergency case description based on ontology, taking the Sunjiawan coal mine "2.14" gas explosion accident in Liaoning province as an example.
\end{abstract} sharing

Keywords-coal mine emergency case; ontology; knowledge

\section{INTRODUCTION}

Coal becomes the important energy with the rapid development of national economy in China, but the situation of safe production of coal mine is very serious. The coal mine safety production has become the focus of attention of the whole society, but there are still many problems existing in the field of coal mine emergency management and rescue work. For example, there is an over-reliance on paper plans during the process of emergency management disposing. It is hard to implement efficient management on emergency by traditional means. Facing emergency, the traditional way can't meet the need, such as accident information responding timely, rescue teams being available timely, which may delay the opportune time to rescue workers. So, in order to improve emergency capability, it is imperative to establish the basic knowledge system of the emergency rescue in the coal production, solve semantic conflicts, and establish coal mine accident knowledge sharing platform.

Ontology, one concept comes from the philosophical field, is introduced in the information science field in the 1990s, which describes the objective existence of the content system in the world. Ontology can describe or express a set of concepts and terminology of one specific knowledge domain and is a set of standardized description used for domain knowledge sharing and reuse. At present, ontology has been widely used in the computer field. By using ontology technology, the coal mine emergency case ontology model can provide the semantic knowledge common understanding of the emergency management process and realize exchanging, sharing, and reusing of the knowledge in the coal mine emergency management fie.

\section{RELATED WORKS}

There have been few reports about coal mine emergency knowledge model and standardization. Emergency domain knowledge modeling varies according to actual requirements. Wang wen-jun described a new $\mathrm{E}^{2} \mathrm{M}$ [1] model based on ABC Ontology model, and listed related concepts of event: event, process, action, situation, state of change, etc. Ref. [2] summarized the emergency domain knowledge model from three aspects: event content, event development, and event control. Ref. [1] divides ontology semantic model of emergency event into three levels: event, process, action to integration emergency events in semantic level, which provides general information exchange model and vocabulary for integrated emergency response system. The above model designs information interaction model in accordance with emergency event and extracts emergency field key elements. The model defines emergency related field classes and class level from their corresponding perspectives and determines the scope and granularity of the emergency domain ontology, then establish the corresponding knowledge model, However, most of these models mainly emphasis process of emergency response, lacking relevant design of internal elements.

Related concepts between coal mine accident emergency handling and coal mine disaster events have a lot in common, but they have different focuses, So we should model emergency case knowledge from the angle of knowledge representation in emergency field, which is more suitable to the need of emergency field.

\section{COAL MINE EMERGENCY CASE ONTOLOGY MODEL}

In this paper, eABC ontology [4] is used as upper ontology in coal mine emergency case knowledge expression, and eABC ontology [4] is expanded to form coal mine emergency case ontology model according to the characteristics of coal mine emergency case knowledge expression. 


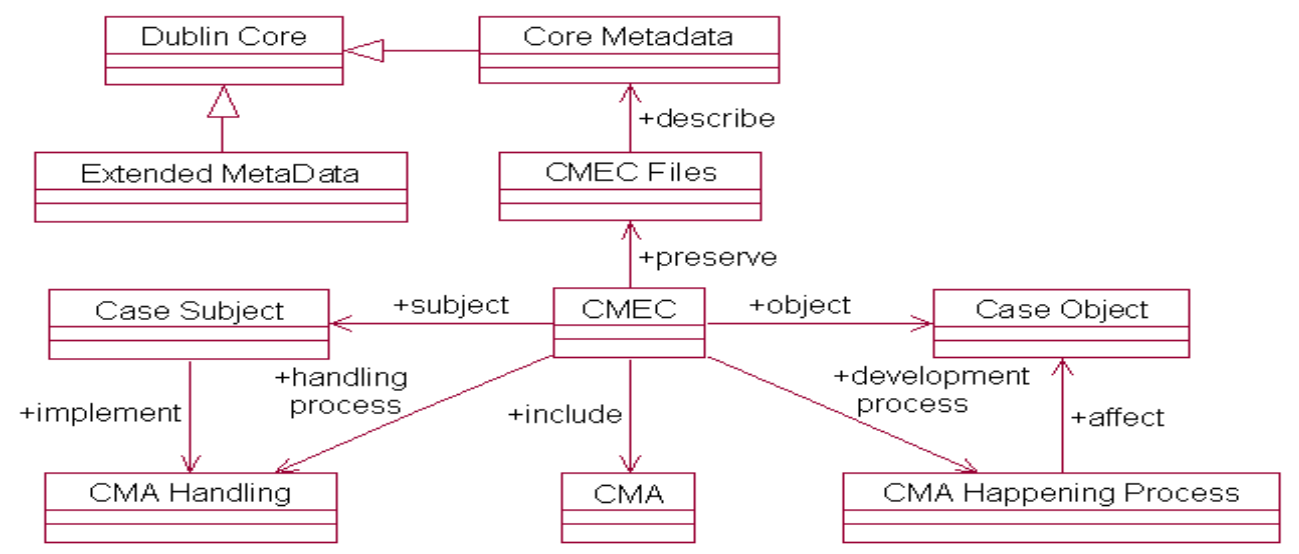

Figure 1. Coal mine emergency case ontology model.

\section{A. Construction of coal mine emergency case ontology}

Coal mine emergency case describes emergency events and their emergency handling process. According to the establishment of ontology concept relationship of document [3], this model adds handling subject and handling object of emergency events, and divides coal mine emergency cases into five sub-ontologies, as is shown in Figure 1 (note of Figure 1: CMEC - coal mine emergency case, CMA—coal mine accident). This ontology model's metadata format uses the Dublin Core Element Set, which is the most widely used element set in the world at present.

Case subject Implementing body of emergency response action, it is made up of emergency organization system and describe the basic component and responsibilities of emergency authorities. It is responsible for the management, scheduling and distribution of emergency resources. It includes emergency management and rescue center, accident Command Center, support and security center, media center, and information processing center.
Case object Describing environment and specific information of coal mine accident area, it is made up of object environment and object area. Case object mainly embodies the time of disasters event and regional characteristics. Various types of disasters and difference of geological condition will also have a certain effect on case object.

Coal mine accident Description of related concepts and events process about coal mine disasters accident, such as event state change of coal mine accident in different periods of time.

Coal mine accident happening process The process takes occurrence, process and the end of accident as its core, define impact factors of emergency response, such as environment, victims, mechanism, and materials.

Coal mine accident emergency handling It is description of coal mine accident emergency handling process, and is the procedure knowledge representation of emergency rescue activity implemented by case subject. It defines different stages and activity during event handling and is the core knowledge expression of emergency case.

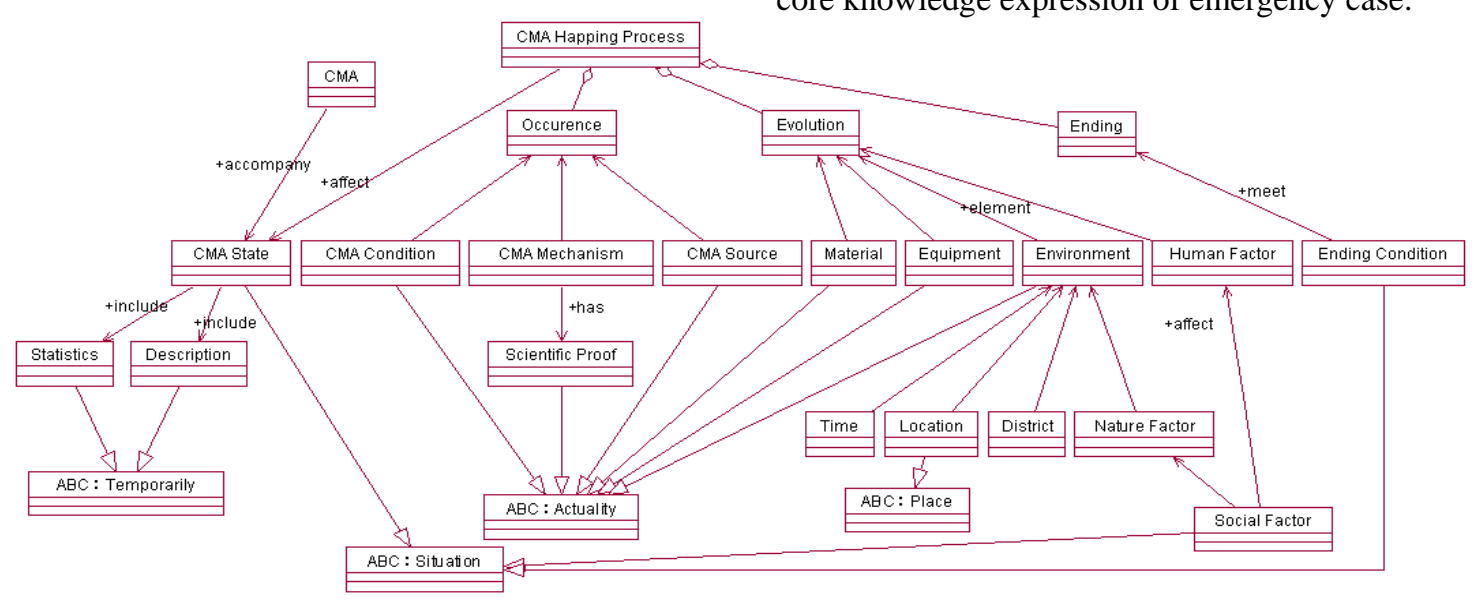

Figure 2. Coal mine accident happening process concept and relation description. 


\section{B. Definition of coal mine emergency case ontology}

- Definition of coal mine emergency case ontology

According to the category of ontology classified by Perez [4], this paper summarized the five basic elements of ontology, which is based on analysis of coal mine emergency case ontology. These elements are: classes, relations, function, axiom, and instances. Classes are called concepts, which refer to any affairs, such as job description, strategy and behavior, Relations refer to interaction between concepts in special field, Function is a special type of relations, Axiom represents real assertion, Instances refer to the specific example of a certain class. Taking the subontology of the model as an example, this paper introduces the five elements of ontology description model.

- The set of coal mine emergency case concept

Sub-ontology of coal mine accidents process modeling process knowledge of emergency rescue events. Because emergency cases are used to recommend knowledge for emergency decisions, it is necessary for us to distinguish this research focuses from coal mine safety science, when describing knowledge of coal mine accidents process. We should pay more attention to elements which has close contact with coal mine accident emergency handling, then we can construct concept model which provides assisted knowledge for emergency response. According to the state of emergency in different stages, coal mine accidents process sub-ontology divides accident process concepts into three concepts groups: accident happening, accident evolution, and accident ending, as is shown in Figure 2 (note of Figure 2: CMA — coal mine accident).

Coal mine accident happening Knowledge set concerning hidden danger and mechanism of accident occurrence during the process of coal mine accident. Related concepts include accident source, accident occurrence mechanism, and accident occurrence condition. Serious accident source is characterized by changing from hidden trouble into accident, reason of accident occurrence is identified by scientific basis, these concepts are the vital event elements during early coal mine accident. Mastering these basic knowledge are good for decision makers to catch the favorable opportunity of emergency handling, and take reasonable and efficient measures to minimize losses.

Accident evolution process The entire process of accident occurrence, accident outbreak, it describes key elements of accident process by phases, determines key problems to be solved in each stage of accident process. Continuously changing of the accident and occurrence of derivative accident have influence on emergency measures and decision-making. The core concepts in the process include: human factors, environmental factors, material factors, electrical and mechanical factors, these are the four basic conditions that influence accident occurrence. Environmental factor refers to circumstances influenced by accident, including location, time, geological conditions, regional features, gas, ventilation condition, and so on. Natural factor (such as climate, environment) and human factor are affected by social factors. Human factor refer to human behavior that influences the accident process. Electrical and mechanical factors refer to the hidden trouble of equipment. Materials reserves are the factors that affect accident protection efficiency. The four factors are key elements of evolution of the accident. As long as we take effective measures to improve the factors that affects the process of accident. The range of effect and the loss should be reduced to the lowest level.

Coal mine emergency handling sub-ontology models emergency handling process and describes the emergency handling process of coal mine accident. Coal mine accident has an evolution process from hidden trouble to major accident. To the mine existing hidden danger, the recognition process always follows the process of coal mine emergency event. The handling of coal mine disaster accident should be based on effective prevention, and cope with potential danger by means of hazard monitoring and hidden danger investigation. The paper constructs emergency accident response model according to the feature of accident process, which includes three concepts group: preventive process, response process, and the end of process, as is shown in Figure 3 (note of Figure 3: CMA — coal mine accident).

Preventive process Accident preventive process including emergency drilling, the major hazard source monitoring, and risk analyses. Emergency drilling are effective precaution measures, its purpose is to make people master rescue and self-rescue procedures when accident happens. Fire, flood, mineral dust, and gas are the main factors that cause coal mine accident, which seriously threaten coal mine safety production, so we should take effective measures to implement supervision to dangerous sources in order to avoid accidents happen. Risk analyses are an important step of emergency plan, and its aim is to give the qualitative or quantitative evaluation results of any accidents that are likely to happen.

Response process The basic aspects of response process include warning action, receiving alarming, judging emergency response level, emergency rescue startup, rescue action, and the end of emergency rescue. Emergency response process models knowledge according to the key elements of emergency rescue process. 


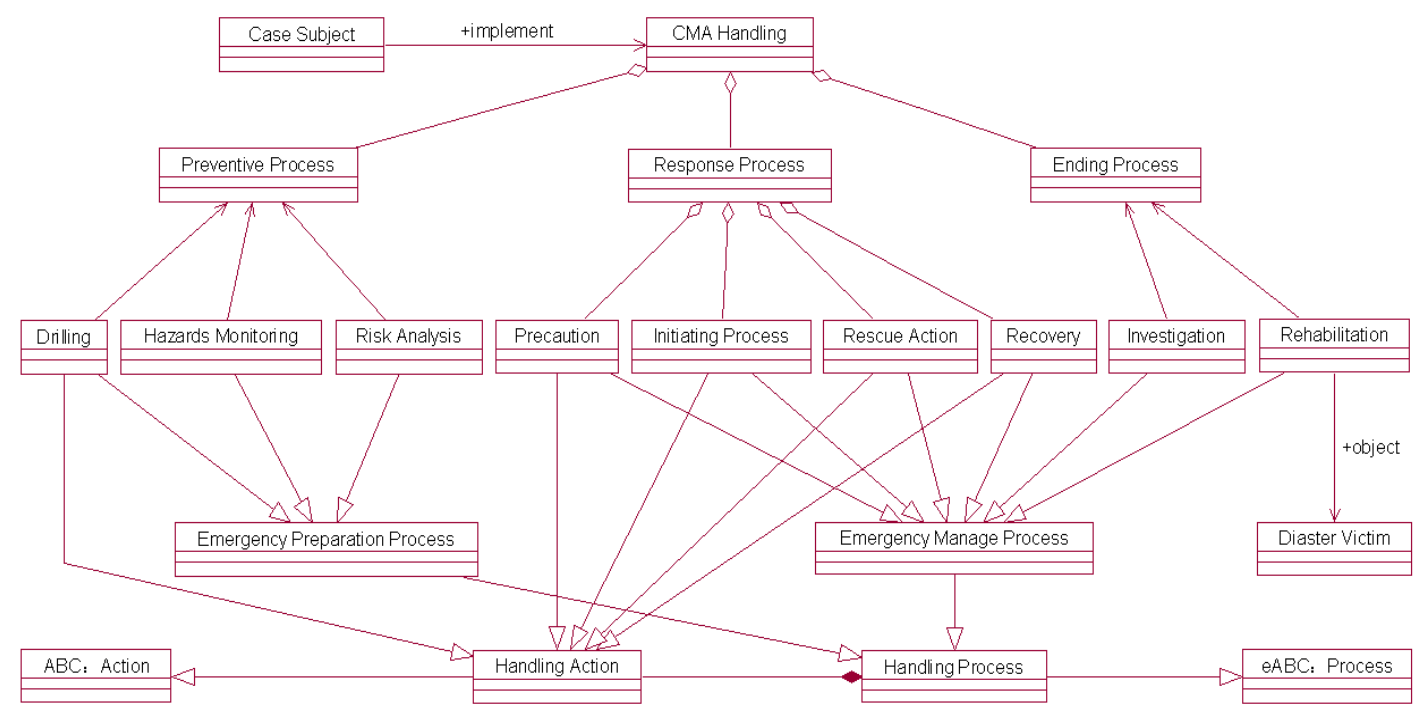

Figure 3. Coal mine accident emergency handling concept and relation description.

\section{The set of coal mine emergency case relations}

In the coal mine emergency case knowledge description, the relation among concepts has three types: association relation, generalization relation, and aggregation relation. Association relation refers to some kind of relationships among the conceptions, including the attribute association and the semantic association. Inheritance relationship refers to the relation between the general and the specific. Aggregation relation refers to the relation between the whole and the part, which comprise a set of elements to a more complex close unit through management.

In specific knowledge expression, association relation is shown in Figures 1 and 2, it includes:

(1) Case subject implement coal mine accident handling
(2) The accident cause mechanism has scientific basis

(3) The process of coal mine accident-affects-case object

(4) End of accident meets the end condition

Generalization relation embodies extensively, as is shown in Figure 3, warning action, emergency startup, rescue action, emergency recovery, accident investigation, and rehabilitation are all sub-process of emergency rescue process, the relation between them are son class and father class. Aggregation relation is obvious in the process of accident, as is shown in Figure 2, accident occurrence, accident evolution, and accident termination are three subprocess of accident process, the relation between coal mine accident and them is whole and parts.

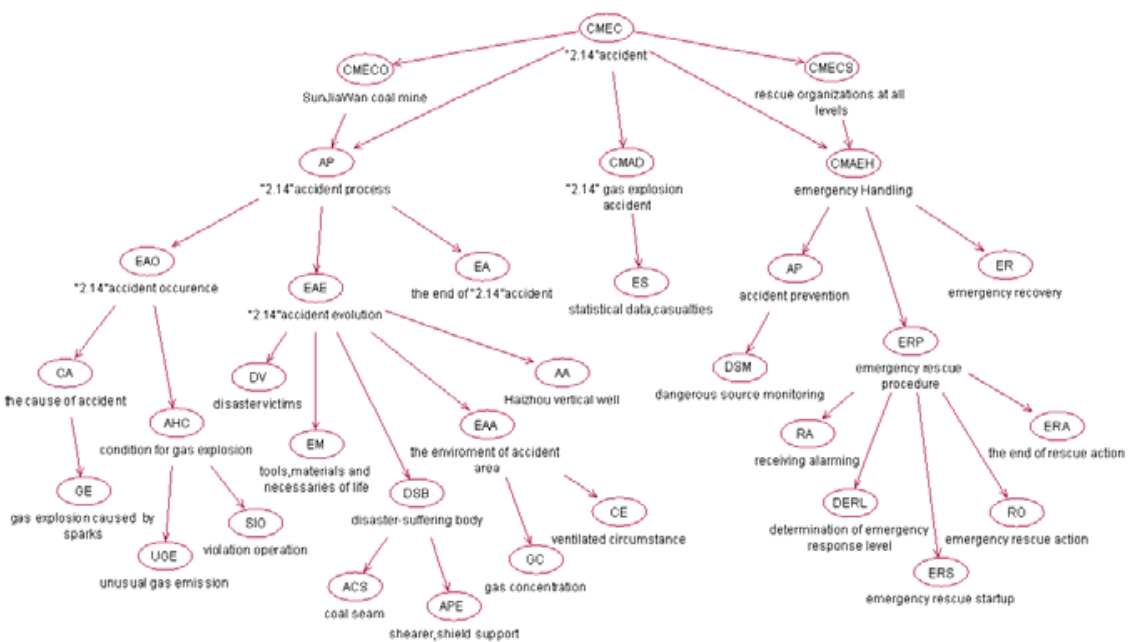

Figure 4. Sunjiawan coal mine "2.14” gas explosion emergency case in Liaoning province information demonstration. 


\section{The set of coal mine emergency case functions}

Function is a special type of relation, it expresses relation's finite constraints on the basis of case relation sets. Relation's previous $n$ - 1 elements of relations can sole determining the $n$th element. event state evolution, cause of the event and the uncertainty of event situation makes difference in coping actions and decision-making in knowledge representation of emergency case. Clearly representation of

emergency case functions sets are the foundation of reasoning about uncertain knowledge. For instance, coal mine safety accidents that have seen 10 or more deaths are identified as major coal mine accident. Description above are function knowledge expression on a specific condition. It is through restricting certain condition of major coal mine accident that constraint result of event level and property. When condition changes, accident condition doesn't fulfill the function, then event level and property should be determined by other functions.

\section{APPLICATION OF COAL MINE EMERGENCY CASE ONTOLOGY MODEL}

Construction of coal mine emergency case ontology model provides good support for exchange, sharing and reuse of case data and case knowledge. Taking Sunjiawan coal mine "2.14" gas explosion accident in Liaoning province as an example, Figure 4 describes some knowledge clips of the accident according to knowledge model that coal mine emergency case ontology model expresses. According to the framework of coal mine emergency case ontology model, Figure 4 extracts four key element from "2.14" gas explosion accident: event objectSunjiawan coal mine accident, event subject-coal mine emergency rescue command center, process of the accident; emergency handling process of accident. In Figure 4, oval represents class of emergency case ontology model, words below represents concrete example, for example, CMEC represents coal mine emergency case, "2.14" gas explosion accident emergency case is the example of the class (Table I).

TABLE 1. NOTES OF Figure 4.

\begin{tabular}{|c|c|}
\hline $\begin{array}{c}\text { CMEC-Coal Mine } \\
\text { Emergency Case }\end{array}$ & $\begin{array}{c}\text { APE-the Affected } \\
\text { Production Equipment }\end{array}$ \\
\hline CMECO-Coal Mine & EAA-he Environment of \\
Emergency Case Object & Accident Area \\
\hline CMAD-Coal Mine & $\begin{array}{c}\text { GC-Gas } \\
\text { Concentration }\end{array}$ \\
Accident Description & CE-Circulation \\
CMECS-Coal Mine & Environment \\
Emergency Case Subject & AA-Accident Area \\
\hline AP-Accident Prevention & ES-Event State \\
\hline EAO-Explosion & CMAEH-Coal Mine Accident \\
Accident Occurrence & Emergency Handling \\
\hline EAE-Explosion & AP-Accident Prevention \\
\hline Accident Evolution & DSM-Dangerous Source \\
\hline EA-the End of Accident & Monitoring \\
\hline CA-the Cause of & \\
\hline
\end{tabular}

\begin{tabular}{|c|c|}
\hline GE-Gas Explosion & $\begin{array}{l}\text { ERP-Emergency Rescue } \\
\text { Process }\end{array}$ \\
\hline $\begin{array}{l}\text { AHC-Accident Happening } \\
\text { Condition }\end{array}$ & RA_-Receiving Alarming \\
\hline $\begin{array}{l}\text { UGE_-Unusual Gas } \\
\text { Emission }\end{array}$ & $\begin{array}{l}\text { DERL-Determination of } \\
\text { Emergency Response Level }\end{array}$ \\
\hline SIO_-Staff Illegal Operation & ERS-Emergency Rescue Startup \\
\hline DV_-Disaster Victim & RO-Rescue Operations \\
\hline $\begin{array}{c}\text { EM-Emergency } \\
\text { Materials }\end{array}$ & $\begin{array}{c}\text { ERA-the End of Rescue } \\
\text { Action }\end{array}$ \\
\hline $\begin{array}{c}\text { DSB_-Disaster-Suffering } \\
\text { Body }\end{array}$ & $\begin{array}{l}\text { ER-Emergency } \\
\text { Recovery }\end{array}$ \\
\hline $\begin{array}{l}\text { ACS-the Affected } \\
\text { Coal Seam }\end{array}$ & \\
\hline
\end{tabular}

Figure 4 sets up a formal semantic expression system based on Coal Mine Emergency Case knowledge sharing system, which standardizes related terms and concepts of emergency cases, and provides convenience for the practical use of domain case knowledge.

\section{CONCLUSION}

According to the characteristics of coal mine accident, this paper models emergency case based on ontology, and extends coal mine accident happening process and accident emergency handling which are core elements in the model. This paper achieves the goal of describing the emergency case normatively and constructing matching knowledge model.

\section{REFERENCES}

[1] W. Wen-jun, L. Xin-peng, L. Ying-wei, et al., Study of ontology and application for emergency event model. Computer Engineering, 31, pp. 10-44, 2005.

[2] J.Z. Hernandez, J.M. Serrano, Knowledge-based models for emergency management systems, Expert Systems with Applications, 20, pp. 173-186, 2001.

[3] M. Sotoodeh, Ontology-based Semantic Interoperability in Emergency Management. University of British, Columbia, 2007.

[4] W. Wen-jun, Y. Peng, D. Cun-xiang, Study and application of emergency case ontology model. Computer Applications, 29(5), pp. 1437-1445, 2009. 